\title{
Pitiose em ovinos nos estados de Pernambuco e Bahia ${ }^{1}$
}

\author{
Manuel V. Carrera ${ }^{2}$, Rodolfo M. Peixoto ${ }^{3 *}$, Gisele V. Gouveia ${ }^{2}$, Clarice R.M. Pessoa ${ }^{2}$, \\ Francielli P.K. Jesus ${ }^{4}$, Janio M. Santurio ${ }^{4}$, Sônia A. Botton ${ }^{5}$ e Mateus M. Costa ${ }^{2}$
}

\begin{abstract}
Carrera M.V., Peixoto R.M., Gouveia G.V., Pessoa C.R.M., Jesus F.P.K., Santurio J.M., Botton S.A. \& Costa M.M. 2013. [Pythiosis in sheep from Pernambuco and Bahia States, Brazil.] Pitiose em ovinos nos estados de Pernambuco e Bahia. Pesquisa Veterinária Brasileira 33(4):476-482. Campus Ciências Agrárias, Universidade Federal do Vale do São Francisco, Rodov. BR 407 Km 12, Lote 543, Projeto de Irrigação Senador Nilo Coelho s/n, Petrolina, PE 56300-990, Brazil. E-mail: rodolfo.peixoto@ifsertao-pe.edu.br

Pythiosis is a devastating infectious disease caused by an aquatic oomycete, Pythium insidioum, and affects animals and humans that inhabit wetlands. The disease is characterized mainly by granulomatous lesions in the hosts. The purpose of this study was to report the occurrence of pythiosis in sheep in the states of Pernambuco (PE) and Bahia (BA), Northeastern Brazil, as well as to evaluate the efficacy of an immunotherapic against ovine pythiosis. Blood samples were collected from 53 sheep, 49 from flocks in counties located in PE and four from BA. Seven sheep showed clinical signs of ovine pythiosis; one of them was submitted to euthanasia and its head and submandibular lymph node was collected and sent for histopathologic and mycological analyses. Other six sheep were treated with an immunotherapic. During the treatment the animals were kept in the Sheep Industry Sector facilities at Univasf/Petrolina-PE. ELISA, fungal culture and polymerase chain reaction (PCR) methods were used to confirm the diagnosis of clinical ovine pythiosis in the sheep flock. At microscopic examination of the material collected from the nasal cavity of a sheep euthanized was observed a focally extensive area of necrosis with presence of diffuse infiltration of intact and degenerated neutrophils bordering the cartilage. Only one sheep showed clinical cure, indicating efficiency in the pythiosis treatment of 16.7\% (1/6). Ovine pythiosis has been increasing in several municipalities of PE and BA. In this context, the immunotherapy may be an alternative to be searched. Therefore, further studies are needed to investigate the effect of immunotherapy on ovine pythiosis.
\end{abstract}

INDEX TERMS: Pythiosis, ELISA, PCR, immunotherapy, sheep.

RESUMO.- A pitiose é uma doença infecciosa causada pelo oomiceto aquático $P$. insidiosum que acomete animais e o homem, especialmente habitantes de áreas úmidas. A enfermidade apresenta como característica principal a for-

\footnotetext{
${ }^{1}$ Recebido em 15 de dezembro de 2012.

Aceito para publicação em 18 de março de 2013.

${ }^{2}$ Campus Ciências Agrárias, Universidade Federal do Vale do São Francisco (Univafs), Rodov. BR 407 Km 12, Lote 543, Projeto de Irrigação Senador Nilo Coelho s/n, Petrolina, PE 56300-990, Brasil.

${ }^{3}$ Campus Floresta, Instituto Federal de Educação, Ciência e Tecnologia do Sertão Pernambucano, Rua Projetada s/n, Caetano II, Floresta, PE 56400-000, Brasil. *Autor para correspondência: rodolfo.peixoto@ifsertao-pe.edu.br

${ }^{4}$ Departamento de Microbiologia e Parasitologia, Centro de Ciências de Saúde, Universidade Federal de Santa Maria (UFSM), Camobi, Santa Maria, RS 97105-900, Brasil.

${ }^{5}$ Departamento de Medicina Veterinária Preventiva, Centro de Ciências Rurais, UFSM, Camobi, Santa Maria, RS.
}

mação de lesões com aspecto granulomatoso nos hospedeiros. Neste trabalho, relatou-se a ocorrência da pitiose em ovinos nos estados de Pernambuco (PE) e Bahia (BA), Nordeste do Brasil, bem como foi avaliada a eficácia de um imunoterápico frente a esta enfermidade. Amostras de sangue de 53 ovinos foram coletadas, sendo 49 animais oriundos de propriedades localizadas em PE e quatro animais provenientes da BA. Sete ovinos demonstraram sinais clínicos de pitiose ovina. Um dos animais foi submetido à eutanásia e sua cabeça e linfonodo submandibular foram coletados e enviados para análises laboratoriais. Seis ovinos foram submetidos à imunoterapia, sendo mantidos nas instalações do setor de ovinocultura da Univasf/Petrolina-PE durante o tratamento. As técnicas de ELISA, cultura fúngica e reação em cadeia da polimerase (PCR) foram utilizadas como métodos diagnósticos da pitiose ovina, sendo 
eficientes para confirmação dos casos clínicos no rebanho. Ao exame microscópico do material coletado da cavidade nasal de um animal eutanasiado, observou-se uma área focalmente extensa de necrose com presença de infiltrado difuso de neutrófilos íntegros e degenerados margeando a cartilagem. Somente um animal apresentou cura clínica, indicando uma eficiência no tratamento da pitiose de $16,7 \%$ (1/6). 0 aumento de casos de pitiose tem sido denotado em diversos municípios de PE e da BA. Neste contexto, o emprego do imunoterápico pode ser uma alternativa a ser pesquisada. Portanto, estudos futuros devem ser realizados para investigar o efeito da imunoterapia aplicada à pitiose em ovinos.

TERMOS DE INDEXAÇÃO: Pitiose, ELISA, PCR, imunoterapia, ovinos.

\section{INTRODUÇÃO}

A pitiose é uma doença infecciosa, causada pelo oomiceto aquático Pythium insidiosum que pertence ao Reino Stramenopila, Filo Oomycota, Classe Oomycetes, Ordem Pythiales, Família Pythiaceae e Gênero Pythium (De Cock et al. 1987). Acomete diversas espécies de animais tais como: bovinos, ovinos, caprinos, cães, gatos e, inclusive, o homem; porém a espécie animal mais atingida é a equina (Tabosa et al. 2004, Mendonza \& Newton 2005, Grecco et al. 2009). A enfermidade não apresenta predisposição para raça, sexo ou idade, (Radostits et al. 2000). É conhecida também como swamp cancer, zigomicose, dermatite granular, bursattee, Florida leeches, granuloma ficomicótico e hifomicose (Chaffin et al. 1995, Foil 1996), ou ainda como ferida da moda nos estados brasileiros do Mato Grosso e Mato Grosso do Sul (Leal et al. 2001a, Frey Jr et al. 2007).

Trata-se de uma doença cosmopolita, ocorrendo com maior frequência em áreas temperadas, tropicais e subtropicais (Grooters 2003). 0 desenvolvimento deste agente ocorre em condições favoráveis de umidade e temperatura variando em torno de 30 a $40^{\circ} \mathrm{C}$, especialmente em locais alagadiços (Miller \& Campbell 1982). Os primeiros relatos dessa enfermidade no Brasil envolveram equinos no Rio Grande do Sul (Santos \& Londero 1974). Em ovinos, os primeiros relatos foram descritos por Tabosa et al. (2004) na Paraíba, onde encontraram casos positivos em animais com lesões ulcerativas nos membros e nas regiões pré-escapulares e abdominal, utilizando a histopatologia e imuno-histoquímica, além da cultura e identificação do agente. Santurio et al. (2008) descreveram rinite granulomatosa associada ao agente, $P$. insidiosum, em ovinos no Mato Grosso. No Piauí, Souza et al. (2008) observaram 14 ovinos acometidos pela pitiose. Portela et al. (2010) descrevem as doenças das fossas nasais diagnosticadas em ruminantes no Hospital Veterinário da Universidade Federal de Campina Grande, em Patos, Paraíba, nos anos de 2003-2009, sendo descritos dois surtos de rinite por P. insidiosum em ovinos.

As características patológicas da enfermidade frequentemente observadas envolvem, principalmente, o aparecimento de lesões com aspecto granulomatoso no tecido cutâneo e subcutâneo. Em equinos são descritas no interior das lesões massas de tecido necrótico de coloração branco-amarelada contendo hifas e infiltrado de eosinófilos, denominados de "Kunkers" (Headley \& Junior 2004, Frey Jr et al. 2007). 0 diagnóstico da pitiose é baseado em sinais clínicos, achados histopatológicos, detecção de anticorpos, isolamento e identificação do agente (Chaffin et al. 1995, Gaastra et al. 2010). 0 diagnóstico diferencial compreende principalmente as seguintes enfermidades: habronemose, zigomicose, neoplasias e granulomas fúngicos ou bacterianos. Os métodos para diagnóstico laboratorial incluem: imuno-histoquímica (Grecco et al. 2009, Pedroso et al. 2009, Gaastra et al. 2010), imunodifusão (Miller \& Campbell 1982), ensaio imunoenzimático - ELISA (Mendoza et al. 1997, Leal et al. 2001b) e os métodos moleculares (Grooters 2002, Schurko et al. 2003, Azevedo et al. 2012). A técnica de ELISA, primeiramente descrita por Mendoza et al. (1997), tem sido empregada como um método seguro e eficaz para o diagnóstico sorológico precoce em humanos e animais. Santurio et al. (2006) utilizaram um teste de ELISA indireto para o diagnóstico da pitiose em eqüinos, sendo observada uma sensibilidade de $97,72 \%$ e especificidade de $90,27 \%$.

0 tratamento é difícil e as principais medidas terapêuticas incluem: cirurgia, imunoterapia e uso de agentes antimicrobianos (Santurio \& Ferreiro 2008). A eficácia dos tratamentos está associada ao tamanho e local da lesão, duração da enfermidade, estado fisiológico e nutricional do hospedeiro acometido (Headley \& Junior 2004). Fármacos isolados ou em associação são empregados como alternativa de terapia em infecções humanas e animais (Hummel et al. 2011, Sudjaritruk et al. 2011, Argenta et al. 2012, Schmiedt et al. 2012). A imunoterapia tem sido outra ferramenta no tratamento da pitiose, mostrando boa eficácia especialmente em equinos infectados (Frey Jr et al. 2007). Um imunoterápico desenvolvido no Brasil vem sendo eficiente no controle da doença em equino, uma vez que altera a resposta imunológica do animal infectado, promovendo a diminuição e a cicatrização das lesões ocasionadas pelo agente (Santurio \& Ferreiro 2008).

Diante da relevância desta enfermidade e com o aumento de casos observados no Brasil, especialmente em animais de produção pecuária, este estudo teve por objetivo relatar a ocorrência da pitiose em ovinos nos estados de Pernambuco (PE) e Bahia (BA), bem como avaliar a eficácia de um imunoterápico frente a esta enfermidade.

\section{MATERIAL E MÉTODOS}

Histórico da enfermidade nas localidades de Pernambuco (PE) e Bahia (BA). Casos clínicos suspeitos de pitiose ocorreram em propriedades rurais criadoras de ovinos dos municípios oriundos dos estados de PE (Afrânio) e BA (Curaçá e Juazeiro), entre os meses de janeiro e abril de 2011. As informações sobre os casos ocorridos da doença em ovinos, primeiramente, foram obtidas junto aos criadores das propriedades acometidas. Em seguida, procedeu-se a realização de exames clínicos in loco e a coleta de amostras nos animais das propriedades avaliadas. 0 sistema de produção era o extensivo, sendo que em todas as criações os ovinos movimentavam-se livremente pela propriedade e ingeriam água proveniente da chuva acumulada em pequenos açudes. 
Obtenção das amostras de soro e análise sorológica por ensaio imunoenzimático. Foram coletadas amostras de sangue de 49 ovelhas, provenientes de quatro propriedades do município de Afrânio (PE) (P1, $n=11$; $P 2, n=13 ; P 3, n=13$ e $P 4, n=12$ ). Adicionalmente, amostras de sangue de quatro ovinos que apresentavam sinais clínicos de pitiose oriundos de um rebanho no município de Curaçá e de três rebanhos em Juazeiro (BA) também foram coletadas. Todas as amostras de sangue foram obtidas por venopunção na jugular sem anticoagulante e acondicionadas em caixas isotérmicas, sendo encaminhadas ao Laboratório de Microbiologia e Imunologia Animal da Universidade Federal do Vale do São Francisco (Univasf) em Petrolina/PE. No laboratório, o material era centrifugado e o soro armazenado a $-20^{\circ} \mathrm{C}$ em tubos de $1,7 \mathrm{ml}$, para posterior remessa ao Laboratório de Pesquisas Micológicas (Lapemi) da Universidade Federal de Santa Maria (UFSM), Rio Grande do Sul (RS), onde foi realizado o teste de ELISA.

As amostras de soro foram analisadas pelo método de ELISA indireto adaptado da metodologia usada por Santurio et al. (2006), sendo empregado um conjugado ovino (diluição de 1:5000) e realizada a leitura em espectofotômetro de microplacas, com filtro de 490nm e Cut-off $=\mu$ DO + 3x s (99,8\% de confiança). As amostras com título acima do ponto de corte foram consideradas positivas para pitiose ovina.

Achados patológicos. Dentre aqueles animais que apresentaram sinais clínicos da enfermidade durante a visita à propriedade, um deles apresentava aumento de volume e úlceras na região do vestíbulo nasal e estava bastante debilitado, sendo encaminhado para a eutanásia. No Laboratório de Patologia Animal da Univasf, os fragmentos da cavidade nasal, linfonodos retrofaríngeos e submandibular foram coletados, fixados em formol a $10 \%$ e encaminhados ao Laboratório de Patologia Animal da Universidade Federal de Campina Grande (UFCG) em Patos na Paraíba (PB). Os cortes foram embebidos em parafina e rotineiramente processados. Lâminas histológicas foram confeccionadas e coradas pela hematoxilina e eosina (HE) e por Grocott.

Isolamento fúngico. Os fragmentos das lesões foram lavados com água destilada estéril com clorafenicol e logo após, lavada com água destilada estéril para a remoção de resíduos deste antibiótico. Todo o material colhido foi semeado em caldo Sabouraud em três frascos estéreis, sendo um com $10 \%$ de cloranfenicol, outro a $20 \%$ de cloranfenicol e outro sem cloranfenicol. Estes foram incubados em agitador automático a $37^{\circ} \mathrm{C}$, durante cinco dias. Ao verificar-se o crescimento de uma estrutura micelial no caldo Sabouraud, um fragmento da colônia foi inoculado em meio mínimo à temperatura ambiente. Após o crescimento da cultura fúngica, 0 micro-organismo foi enviado para análise molecular.

Análise molecular pela reação em cadeia da polimerase (PCR). Para a confirmação molecular de pitiose ovina, primeiramente foi extraído o DNA total da massa fúngica proveniente do isolado. Os iniciadores específicos PI1(TCCGTCGAAGCGGACTGCT) e PI2 (GCCGTACAACCCGAGAGTCATA) (Grooters \& Gee, 2002) foram utilizados para amplificação de um fragmento da região intergenic transcribed spacer 1(ITS1) do RNA ribossomal (rDNA) de Pythium insidiosum da amostra previamente isolada. Como controle positivo foi empregado o DNA da amostra padrão de $P$. insidiosum CBS 101555. No preparo da PCR foram empregadas as mesmas condições anteriormente descritas por Botton et al. (2011). Em seguida os produtos de amplificação foram analisados em gel agarose a $2 \%$ e visualizados sobre iluminação UV.

Imunoterapia. A imunoterapia foi empregada em seis fêmeas ovinas oriundas dos municípios de Afrânio (PE), Juazeiro e Curaçá (BA), os quais foram encaminhados para as instalações do setor de ovinocultura da Univasf em Petrolina/PE. O imunoterápico (Pitium-Vac ${ }^{\circledR}$ ), desenvolvido em colaboração da Embrapa e Lape-
mi/UFSM (Santurio et al. 1998) foi aplicado por via subcutânea na região pré-escapular, sendo utilizada uma dose de $2 \mathrm{~mL}$ em intervalos de 14 dias naqueles animais que apresentaram sinais clínicos e anticorpos anti-P. insidiosum detectados pelo teste de ELISA ( $n=6)$. Os animais foram acompanhados para avaliação da evolução da enfermidade.

\section{RESULTADOS}

Histórico da enfermidade e sinais clínicos dos ovinos nas localidades de Pernambuco (PE) e Bahia (BA). Os animais comumente apresentavam aumento de volume em uma das narinas e dificuldade respiratória e ocorria a morte entre 15 e 30 dias a partir da observação dos sinais clínicos. Ao exame clínico de um animal afetado, observou-se aumento de volume na região nasal e a presença de secreção serosanguinolenta bilateral (Fig.1). Também foi denotada a presença de fístula no palato duro, ligando o vestíbulo nasal à cavidade oral, bem como se percebeu odor desagradável e anorexia neste animal. Os casos relatados pelos produtores foram casos isolados e mais frequentemente relacionados com as épocas chuvosas ou logo após este período.

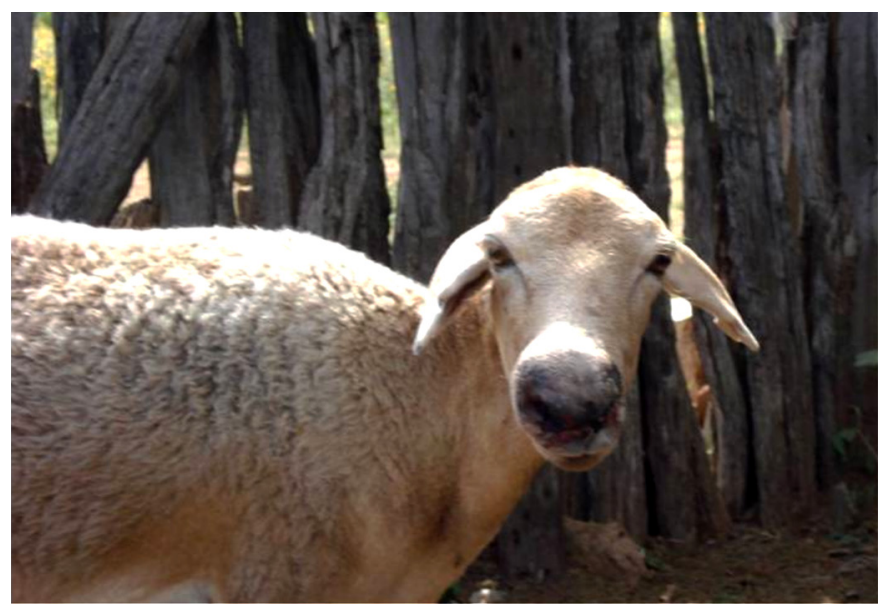

Fig.1. Fêmea ovina com sinais clínicos de pitiose, apresentando visível aumento de volume na face, região do focinho.

Dentre os 49 ovinos do município de Afrânio (PE), três animais apresentavam sinais clínicos condizentes com pitiose. No município de Curaçá (BA) encontrou-se um animal com manifestação clínica desta enfermidade e, no município de Juazeiro (BA), evidenciaram-se três ovinos com sinais compatíveis (Quadro 1).

Análise sorológica pelo ELISA. No ELISA, das 49 amostras de soro provenientes do município de Afrânio (PE), 15 animais apresentaram anticorpos anti-Pythium insidiosum (Quadro 2). Posteriormente, outros quatro animais provenientes dos municípios de Curaçá (BA) (n=01) e Juazeiro (BA) $(n=03)$, também foram positivos no teste sorológico. Todos os casos de animais apresentando sinais clínicos compatíveis com a pitiose foram confirmados pela sorologia com o emprego do teste de ELISA indireto.

Achados patológicos. Após a secção da cabeça do animal eutanasiado, pode-se verificar uma área de necrose rostralmente na narina e uma área de tecido inflamatório 
Quadro 1. Sinais clínicos observados em sete fêmeas ovinas criadas em propriedades rurais de Pernambuco e Bahia

\begin{tabular}{|c|c|}
\hline Município (Estado) & Sinais clínicos \\
\hline Afrânio (PE) & $\begin{array}{l}\text { Aumento de volume na região nasal e secreção } \\
\text { serosa }\end{array}$ \\
\hline Afrânio(PE) & $\begin{array}{l}\text { Aumento de volume na região nasal e subman- } \\
\text { dibular, fístula oronasal e secreção mucopuru- } \\
\text { lenta }\end{array}$ \\
\hline Afrânio (PE) & $\begin{array}{l}\text { Aumento de volume na região nasal e secreção } \\
\text { serosa }\end{array}$ \\
\hline Riacho Seco/Curaçá (BA) & $\begin{array}{l}\text { Aumento de volume na região nasal, secreção } \\
\text { serosanguinolenta, fístula oronasal, dispnéia e } \\
\text { miíase nasal }\end{array}$ \\
\hline Pinhões/Jur & $\begin{array}{l}\text { Aumento de volume na região nasal, secreção, } \\
\text { serosanguinolenta e fístula oronasal }\end{array}$ \\
\hline Pinhões/Juazeiro (BA) & $\begin{array}{l}\text { Aumento de volume na região nasal, secreção, } \\
\text { serosanguinolenta e fístula oronasal }\end{array}$ \\
\hline Pinhões/Juazeiro (BA) & $\begin{array}{l}\text { Aumento de volume na região nasal, secreção, } \\
\text { serosanguinolenta e fístula oronasal }\end{array}$ \\
\hline
\end{tabular}

Quadro 2. Detecção de anticorpos anti-Pythium insidiosum em propriedades de Afrânio (PE)

\begin{tabular}{cccc}
\hline Propriedade & $\begin{array}{c}\text { Número de animais } \\
\text { testados (ELISA) }\end{array}$ & $\begin{array}{c}\text { Histórico de } \\
\text { casos suspeitos }\end{array}$ & $\begin{array}{c}\text { Número de animais } \\
\text { positivos por pro- } \\
\text { priedade (\%) }\end{array}$ \\
\hline P1 & 11 & Não & $05(45,4 \%)$ \\
P2 & 13 & Sim & $04(30,7 \%)$ \\
P3 & 13 & Não & $03(23,1 \%)$ \\
P4 & 12 & Sim & $03(25 \%)$
\end{tabular}

se estendendo por toda cavidade nasal. Observou-se também ulceração e perda de tecido do palato duro, formando uma fístula oronasal com aproximadamente dois $\mathrm{cm}$ de diâmetro. No exame microscópico do material coletado da cavidade nasal notou-se uma área focalmente extensa de necrose com presença de infiltrado difuso de neutrófilos íntegros e degenerados margeando a cartilagem. Tanto nos linfonodos quanto nas lesões da cavidade nasal observaram-se estruturas tubuliformes longitudinais e transversais não coradas, margeadas por material eosinofílico radiado (Splendore-Hoeppli). Circundado essas áreas, denotou-se infiltrado inflamatório, constituído por neutrófilos, linfócitos, plasmócitos, macrófagos, células epitelióides e células gigantes, e discreta proliferação de tecido fibroso. Em algumas áreas foi possível verificar infiltrado neutrofílico moderado. Também foram encontradas áreas multifocais de mineralização. No material de cavidade nasal e linfonodo retrofaríngeo, observou-se estruturas com morfologia compatível com hifas fúngicas de diâmetro variando de 0,3 a $0,7 \mathrm{~cm}$, com parede espessa e irregular, raramente septadas e ramificadas, e algumas vezes em ângulo reto.

Isolamento fúngico e PCR. A partir dos fragmentos coletados do animal submetido à eutanásia foi visualizado, após o quinto dia de cultivo, o crescimento de uma estrutura micelial, compatível com o oomiceto aquático Pythium insidiosum. A partir do isolado fúngico, procedeu-se a extração de DNA total e a PCR com o emprego de iniciadores específicos para a amplificação de um fragmento da região ITS1, produzindo um produto com tamanho de aproximadamente 105 pares de base, conforme, também, observado por Botton et al. (2011).
Imunoterapia. Dos animais que receberam as aplicações do imunoterápico, somente uma ovelha proveniente do município de Afrânio (PE) sobreviveu e apresentou regressão da lesão, indicando uma eficácia no tratamento da pitiose de 16,7\% (Quadro 3). Os animais que morreram apresentavam um grau avançado de comprometimento nasal e encontravam-se bastante debilitados.

A evolução terapêutica do ovino que apresentou recuperação clínica está descrita no quadro 4. Após 14 dias da segunda dose do imunoterápico o animal ainda apresentava uma ulceração da mucosa nasal e aumento da narina direita (Fig.2). Foi observado o desaparecimento da úlcera após a terceira dose do imunoterápico, havendo uma diminuição do edema da narina direita, permanecendo deste modo até a quinta e última dose da imunoterapia.

Quadro 3. Ovinos tratados com imunoterápico contra pitiose: casos de infecção natural em Pernambuco e Bahia

\begin{tabular}{ccc}
\hline $\begin{array}{c}\text { Identificação } \\
\text { do animal }\end{array}$ & $\begin{array}{c}\text { Numero de doses } \\
\text { (14 dias de intervalo) }\end{array}$ & Resultado \\
\hline 01 & 05 & Recuperado \\
02 & 03 & Óbito \\
03 & 03 & Óbito \\
04 & 03 & Óbito \\
05 & 01 & Óbito \\
06 & 02 & Óbito
\end{tabular}

Quadro 4. Evolução dos sinais clínicos observados em ovino submetido ao tratamento da pitiose com o imunoterápico Pitium-VAC ${ }^{\circledR}$

\begin{tabular}{|c|c|}
\hline № de aplicações & Sinais clínicos \\
\hline 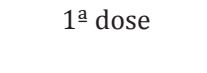 & $\begin{array}{l}\text { Aumento de volume na região nasal, secreção serosa, ri- } \\
\text { nite, dispnéia leve }\end{array}$ \\
\hline $2^{a}$ dose & $\begin{array}{l}\text { Aumento de volume na região nasal, secreção serosa dimi- } \\
\text { nuída, rinite, dispnéia leve, aparecimento de úlcera na- } \\
\text { sal (aproximadamente } 0,3 \mathrm{~cm} \text { de diâmetro) }\end{array}$ \\
\hline $3^{\text {a }}$ dose & $\begin{array}{l}\text { Edema nasal reduzido, ausência de secreção serosa, desa- } \\
\text { parecimento de úlcera nasal }\end{array}$ \\
\hline $4^{\mathrm{a}}$ dose & Diminuição progressiva do edema nasal \\
\hline $5^{\mathrm{a}}$ dose & Animal com leve aumento nasal na narina direita \\
\hline
\end{tabular}

\section{DISCUSSÃO}

Neste trabalho, animais oriundos de propriedades de Pernambuco (PE) e Bahia (BA), onde havia suspeita de pitiose, tinham livre acesso a açudes, nos quais também foi denotada a presença de gramíneas. Condições similares foram observadas por Tabosa et al. (2004) os quais confirmaram casos de pitiose em ovinos na Paraíba, que alimentavam-se de pasto verde na superfície de um açude e estavam mantidos próximos a um lago.

Os achados clínicos e patológicos encontrados foram semelhantes aqueles observados por outros pesquisadores (Santurio et al. 2008, Souza et al. 2008) que descreveram o aumento da narina, face e lábio superior, além da presença de secreção serosanguinolenta e dispnéia em ovinos. Nos animais acompanhados durante este estudo também foram observadas lesões e deformidade facial cursando com necrose e fístulas, localizadas no palato duro e septo nasal na região média rostral da cavidade nasal.

Observou-se que todos os casos de animais apresentando sinais clínicos compatíveis com a pitiose foram confir- 


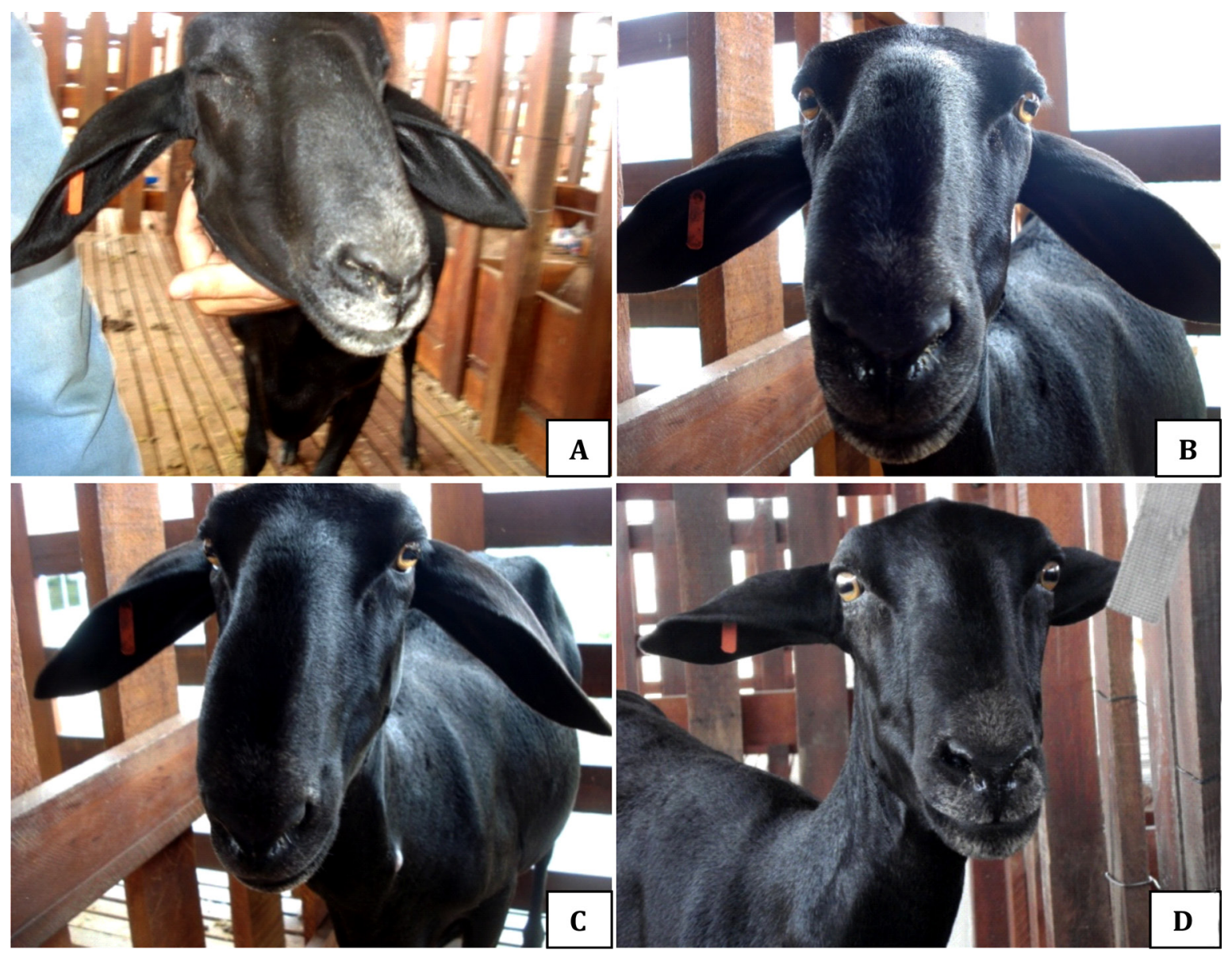

Fig.2. Evolução dos sinais clínicos em ovino após aplicação de imunoterápico. (A) Fêmea ovina 14 dias após a segunda aplicação do imunoterápico. (B) 14 dias após a terceira aplicação. (C) 14 dias após a quarta aplicação. (D) 14 dias após a quinta aplicação.

mados pela sorologia com o emprego do teste de ELISA indireto. Este teste tem sido utilizado para a identificação de anticorpos contra a pitiose em humanos e animais, por ser considerado um método seguro e eficaz, também demonstrando boa sensibilidade e especificidade para o diagnóstico desta enfermidade (Mendonza et al. 1997, Santurio et al. 2006). No pantanal sul-matogrossense, Leal et al. (2001a) confirmaram, por meio do ELISA, 16 casos de equinos com lesões cutâneas ou subcutâneas localizadas nos membros, na face e na porção ventral da parede tóraco-abdominal. A sorologia indireta é considerada um método não invasivo e que não possui um custo elevado para o uso no diagnóstico de enfermidades infecciosas sistêmicas (Grooters 2002). Na Tailândia, o ELISA foi empregado com sucesso para diagnosticar pitiose humana em um paciente talassêmico (Vanittanakom et al. 2004). Gabriel et al. (2008) pesquisando a pitiose num grupo de bovinos sem raça definida verificaram que oito animais foram reagentes no teste de ELISA. Naquele estudo, o ELISA foi mais eficaz do que a cultura para o diagnóstico da pitiose bovina.

0 cultivo fúngico seguido pelo diagnóstico molecular auxiliaram na confirmação da pitiose ovina. A PCR confirmou a suspeita de pitiose da ovelha eutanasiada, empregando inciadores específicos e produzindo a amplificação da região-alvo ITS1 do rDNA da amostra, sendo visualiza- da uma banda de tamanho esperado (105 pb). A técnica de PCR é bastante confiável, sendo específica e eficaz para identificar este patógeno (Grooters \& Gee 2002, Botton et al. 2011). Santurio et al. (2008) também empregaram a PCR para confirmar os casos de pitiose em ovinos. Trost et al. (2009) do mesmo modo utilizaram a PCR para identificar o agente etiológico em um caso de pitiose intestinal canina em Santa Maria/RS. A análise molecular demonstrou ser eficiente para confirmar a infecção natural de $100 \%$ (21/21) dos equinos e a infecção experimental em 64,28\% $(18 / 28)$ dos coelhos avaliados, a partir da análise de amostras de "kunkers" e tecidos, respectivamente (Botton et al. 2011).

A imunoterapia tem sido descrita com uma alternativa de tratamento de pitiose, especialmente em equinos e humanos (Krajaejun et al. 2006, Gaastra et al. 2010, Sudjaritruk et al. 2011). Hensel et al. (2003) relataram que a associação da imunoterapia com a cirurgia e o uso de antimicrobianos obteve maiores índices de cura do que a cirurgia e terapia antifúngica empregadas individualmente. Nesta pesquisa, optou-se somente pelo emprego do imunoterápico, especifico para uso em equinos, em seis fêmeas ovinas em diferentes estágios da enfermidade. A imunoterapia mostrou-se eficaz em apenas uma ovelha, após aplicação de cinco doses, em intervalos de quatorze 
dias. 0 protocolo empregado foi o mesmo indicado para a terapia em equinos. Evidenciou-se a diminuição do edema nasal e da secreção, havendo a recuperação clínica deste animal. 0 imunoterápico foi empregado no estágio inicial da doença, o que neste caso, pode ter sido um dos fatores cruciais para a eficácia do tratamento deste ovino. De acordo com Santurio \& Ferreiro (2008), quando os antígenos do imunoterápico são injetados no corpo do animal infectado por Pythium insidiosum, haverá o desencadeamento de uma resposta imune celular, ativando especialmente os linfócitos T e os macrófagos, que promovem a destruição e danos às hifas. Além disso, as citocinas também podem induzir resposta de linfócitos B e IgG. No entanto, muitos aspectos da resposta imune do hospedeiro, bem como fatores relacionados ao agente etiológico necessitam ser esclarecidos.

Existem diversas pesquisas enfocando a espécie mais acometida pela infecção, a equina, porém os estudos com ruminantes são escassos. 0 emprego da imunoterapia tem se mostrado bastante eficiente em equinos acometidos pela pitiose (Mendonza et al. 2003, Frey Jr et al. 2007). Mendonza et al. (2003) obtiveram a cura de pitiose cutânea de 13 equinos dentre 18 animais testados, utilizando várias doses do imunoterápico. Em outro trabalho, no qual dez casos de pitiose equina foram observados em Pelotas/RS, com diferentes sinais clínicos, cinco destes animais apresentaram recuperação após a aplicação do imunoterápico (Frey Jr et al. 2007). Em cães, a imunoterapia tem gerado resultados promissores (Mendoza et al. 2003), especialmente quando há combinação com outras formas de tratamentos, sobretudo havendo a associação com a quimioterapia (Hensel et al. 2003, Hummel et al, 2011, Schmiedt et al. 2012). Com o número crescente de relatos de pitiose em criações de ovinos no Brasil, há necessidade de pesquisas futuras a fim de buscar alternativas terapêuticas no controle desta importante enfermidade.

\section{CONCLUSÃO}

Neste trabalho, relata-se a presença da pitiose em ovinos provenientes de municípios de Pernambuco e Bahia. Observou-se que os testes de ELISA e PCR são importantes ferramentas, que quando utilizadas em conjunto, fornecem uma maior segurança no diagnóstico da pitiose na espécie ovina. Novos estudos relacionados à imunoprofilaxia da pitiose em ovinos precisam ser realizados, bem como a pesquisa de fatores relacionados à interação agente-hospedeiro.

Agradecimentos.- Ao professor Franklin Riet-Correa, Centro de Saúde e Tecnologia Rural, Campus de Patos, Universidade Federal de Campina Grande (UFCG); ao professor Aldrin Ederson Vila Nova Silva, Universidade Federal do Vale do São Francisco (Univasf), e ao graduando em Medicina Veterinária, Marcos A.D. Macêdo (Univasf) pela valiosa ajuda neste trabalho.

\section{REFERÊNCIAS}

Argenta J.S., Alves S.H., Silveira F., Maboni G., Zanette R.A., Cavalheiro A.S., Pereira P.L., Pereira D.I.B., Sallis E.S.V., Pötter L., Santurio J.M. \& Ferreiro L. 2012. In vitro and in vivo susceptibility of two-drug and three-drug combinations of terbinafine, itraconazole, caspofungin, ibuprofen and fluvastatin against Pythium insidiosum. Vet. Microbiol. 157:137-142
Azevedo M.I., Botton S.A., Pereira D.I.B., Robe L.J., Jesus F.P.K., Mahl C.D., Costa M.M., Alves S.H. \& Santurio J.M. 2012. Phylogenetic relationships of Brazilian isolates of Pythium insidiosum based on ITS rDNA and cytochrome oxidase II gene sequences. Vet. Microbiol. 159:141-148.

Botton S.A., Pereira D.I.P., Costa M.M., Azevedo M.I., Argenta J.S., Jesus F.P.K., Alves S.H.S. \& Santurio J.M. 2011. Identification of Pythium insidiosum by Nested PCR in cutaneous lesions of brazilian horses and rabbits. Curr. Microbiol. 62:1225-1229.

Chaffin M.K., Schumacher J. \& McMullan W.C. 1995. Cutaneous pythiosis in the horse. Vet. Clin. North Am., Equine Pract. 11(1):91-103.

De Cock A.W.A.M., Mendonza L., Padhye A.A., Ajello L. \& Kaufman L. 1987. Pythium insidiosum sp. nov., the etiologic agent of pythiosis. J. Clin. Microbiol. 25(2):344-349.

Foil C.S. 1996. Update on pythiosis (Oomycosis). Proc. North American Veterinary Conference, Orlando, EUA, p.57-63.

Frey Jr F., Velho J.R., Lins L.A., Nogueira C.F.W. \& Santurio J.M. 2007. Pitiose equina na região sul do Brasil. Revta Port. Ciênc. Vet. 102(561/562):107111.

Gaastra W., Lipman L.J.A., De Cock A.W.A.M., Exel T.K., Pegge R.B.G., Scheuwater J., Vilela R. \& Mendoza L. 2010. Pythium insidiosum: an overview. Vet. Microbiol. 146:1-16.

Gabriel A.L., Kommers G.D., Trost M.R., Barros C.S.L., Pereira D.B., Schwendler S.E. \& Santurio J.M. 2008. Surto de pitiose cutânea em bovinos. Pesq. Vet. Bras. 28(12):583-587.

Grecco F.B., Schild A.L., Quevedo P., Assis-Brasil N.D., Kommers G.D., Marcolongo-Pereira C. \& Soares M.P. 2009. Pitiose cutânea em bovinos na região Sul do Rio Grande do Sul. Pesq. Vet. Bras. 29(11):938-942.

Grooters A.M. 2002. New diagnostic tests for pythiosis. Vet. Med. 97(7): 503-504.

Grooters A.M. 2003. Pythiosis, lagenidiosis and zygomycosis in small animals. Vet. Clin. North Am., Small Anim. Pract. 33(4):695-720.

Grooters A.M. \& Gee M.K. 2002. Development of a nested polymerase chain reaction assay for the detection and identification of Pythium insidiosum. J. Vet. Intern. Med. 16:147-152.

Headley S.A \& Junior H.N.A. 2004. Equine cutaneous pythiosis: a report of four cases. Ciência Rural 34(1):289-292.

Hensel P., Greene C.E., Medleu L., Latimer K.S. \& Mendoza L. 2003. Immunotherapy for treatment of multicentric cutaneous pythiosis in a dog. J. Am. Vet. Med. Assoc. 223:215-218.

Hummel J., Grooters A., Davidson G., Jennings S., Nicklas J. \& Birkenheuer A. 2011. Successful management of gastrointestinal pythiosis in a dog using itraconazole, terbinafine, and mefenoxam. Med. Mycol. 49:539542.

Krajaejun T., Sathapatayavongs B., Pracharktam R., Nitiyanant P., Leelachaikul P., Wanachiwanawin W., Chaiprasert A., Assanasen P., Saipetch M., Mootsikapun P., Chetchotisakd P., Lekhakula A., Mitarnun W., Kalnauwakul S., Supparatpinyo K., Chaiwarith R., Chiewchanvit S., Tananuvat N., Srisiri S., Suankratay C., Kulwichit W., Wongsaisuwan M. \& Somkaew S. 2006. Clinical and Epidemiological analyses of human Pythiosis in Thailand. Clin. Infect. Dis. 43: 569-576.

Leal A.B.M., Leal A.T., Santurio J.M., Kommers G.D. \& Catto J.B. 2001a. Pitiose equina no pantanal brasileiro: Aspectos clínicos-patológicos de casos típicos e atípicos. Pesq. Vet. Bras. 21(4):151-156.

Leal A.T., Leal A.B.M., Flores E.F. \& Santurio J.M. 2001b. Pitiose - Revisão bibliográfica. Ciênc. Rural 31(4):735-743.

Mendonza L., Mandy W. \& Glass R. 2003. An improved Pythium insidiosum-vaccine formulation with enhanced immunotherapeutic properties in horses and dogs with pythiosis. Vaccine 21:2797-2804.

Mendoza L. \& Newton J.C. 2005. Immunology and immunotherapy of the infections caused by Pythium insidiosum. Med. Mycol. 43:477-486.

Mendoza L., Kaufman L., Mandy W. \& Glass R. 1997. Serodiagnosis of human and animal pythiosis using an enzyme-linked immunosorbent assay. Clin. Diagn. Lab. Immunol. 4(6):715-718.

Miller R.I. \& Campbell R.S.F. 1982. Clinical observations on equine phycomycosis. 1982. Aust. Vet. J. 58:221-226. 
Pedroso P.M.O., Dalto A.G.C., Raymundo D.L., Bezerra Júnior P.S., Bandara P.M., Oliveira E.C., Sonne L. \& Driemeier D. Rinite micótica nasofaríngea em um ovino Texel no Rio Grande do Sul. 2009. Acta Scient. Vet. 37(2):181-185.

Portela R.A., Riet-Correa F., Garino Jr F., Garino Jr F., Dantas A.F.M., Simões S.V.D. \& Silva S.M.S. 2010. Doenças da cavidade nasal em ruminantes no Brasil. Pesq. Vet. Bras. 30(10):844-854.

Radostits O.M., Gay C.C., Blood D.C. \& Hinchcliff K.W. 2000. Clínica Veterinária - Um Tratado de Doenças dos Bovinos, Ovinos, Suínos, Caprinos e Equinos. 9aㅡ. Ed. Guanabara Koogan, Rio de Janeiro. 1731p.

Santos M.N. \& Londero A.T. 1974. Zigomicose subcutânea em cavalos. Pesq. Agropec. Bras. 9:7-8.

Santurio J.M., Monteiro A.B., Leal A.T., Kommers G.D., Sousa R.S. \& Catto J.B. 1998. Cutaneous pythiosis insidiosi in calves from the pantanal region of Brazil. Mycopathologia 141:123-125.

Santurio J.M., Leal A.T., Leal A.B.M., Alves S.H., Lübeck I., Griebeler J. \& Copetti M.V. 2006. Teste de ELISA indireto para o diagnóstico sorológico de pitiose. Pesq. Vet. Bras. 26(1):47-50.

Santurio J.M. \& Ferreiro L. 2008. Pitiose: uma abordagem micológica e terapêutica. Universidade Federal do Rio Grande do Sul, Porto Alegre. 111p.

Santurio J.M., Argenta J.S., Schwendler S.E., Cavalheiro A.S., Pereira D.I.B., Zanete R.A., Alves S.H., Dutra V., Silva M.C., Arruda L.P., Nakazato L. \& Colodel E.M. 2008. Granulomatous rhinitis associated with Pyhtium insidiosum infection in sheep. Vet. Rec. 163(1):276-77.
Schurko A., Mendoza L., De Cock A.W.A.M. \& Klassen G.R. 2003. Evidence for geographic clusters: molecular genetic differences among strains of Pythium insidiosum from Asia, Australia and the Americas are explored. Mycologia 95(2):200-208.

Schmiedt C.W., Stratton-Phelps M., Torres B.T., Bell D., Uhl E.W., Zimmerman S., Epstein J. \& Cornell K.K. 2012. Treatment of intestinal pythiosis in a dog with a combination of marginal excision, chemotherapy, and immunotherapy. J. Am. Vet. Med. Assoc. 241:358-363.

Sudjaritruk T. \& Sirisanthana V. 2011. Successful treatment of a child with vascular pythiosis. BMC Infect Dis. 11:33.

Souza F.A.L., Souza A.B., Sousa Júnior A., Costa F.A.L., Riet-Correa F., Mendoza L., Carvalho E.M.S. \& Silva S.M.M.S. 2008. Pitiose em ovinos no estado do Piauí. Anais 35o Conbravet, Gramado, RS, p.1-6. (Resumo)

Tabosa I.M., Riet-Correa F., Nobre V.M., Azevedo E.O., Reis-Júnior J.L. \& Medeiros R.M. 2004. Outbreaks of pythiosis in two flocks of sheep in northeastern Brazil. Vet. Pathol. 41:412-415.

Trost M.E., Gabriel A.L., Masuda E.K., Fighera R.A., Irigoyen L.F. \& Komers G.D. 2009. Aspectos clínicos, morfológicos e imuno-histoquímicos da pitiose gastrintestinal canina. Pesq. Vet. Bras. 29(8):673-679.

Vanittanakom N., Supabandhu J., Khamwam C., Praparattanapan J., Thirach S., Prasertwitayakij N., Louthrenoo W., Chiewchanvit S. \& Tananuvat N.V. 2004. Identification of Emerging Human-Pathogenic Pythium insidiosum by Serological and Molecular Assay-Based Methods. J. Clin. Microbiol. 42(9):3970-3974. 